\title{
The comparison of dexmedetomidine and midazolam used for sedation of patients during upper endoscopy: A prospective, randomized study
}

\author{
Yavuz Demiraran $M D^{1}$, Esin Korkut $\mathrm{MD}^{2}$, Ali Tamer $\mathrm{MD}^{3}$, Ilknur Yorulmaz MD ${ }^{1}$, \\ Buket Kocaman MD ${ }^{1}$, Gulbin Sezen MD ${ }^{1}$, Yusuf Akcan $M^{3}$
}

\begin{abstract}
Y Demiraran, E Korkut, A Tamer, et al. The comparison of dexmedetomidine and midazolam used for sedation of patients during upper endoscopy: A prospective, randomized study. Can J Gastroenterol 2007;21(1):25-29.
\end{abstract}

The aim of the present prospective, randomized study was to investigate and compare the safety and efficacy of dexmedetomidine versus midazolam in providing sedation for gastroscopy. A total of 50 adult patients (25 patients receiving dexmedetomidine and 25 patients receiving midazolam), 18 to 60 years of age, and rated I and II on the American Society of Anesthesiologists physical status classification system were included. A brief questionnaire was used to collect demographic data; patients were asked to rate anxiety, satisfaction with care to date and expected discomfort on a visual analogue scale. The following parameters were measured continuously and recorded every minute: heart rate, mean arterial pressure, hemoglobin oxygen saturation and respiratory rate. The two groups were similar with regard to age, body mass index, sex, education, duration of endoscopy, and ethanol or tobacco use. After the procedure, full recovery time, mean arterial pressure, heart rate, respiratory rate and hemoglobin oxygen saturation levels were similiar in both groups. Both groups also had low levels of perceived procedural gagging, discomfort and anxiety scores $(P>0.05)$, and high satisfaction levels $(90.1 \pm 3.0$ for dexmedetomidine versus $84.9 \pm 4.5$ for midazolam; $\mathrm{P}>0.05$ ). Retching and endoscopist satisfaction were significantly different in patients receiving dexmedetomidine versus those receiving midazolam $(88.8 \pm 6.5$ versus $73.5 \pm 16.4, \mathrm{P}<0.05$; and $20.6 \pm 4.4$ versus $45.2 \pm 6.0$; $\mathrm{P}<0.001)$. In the midazolam group, the number of patients who had adverse effects was higher than the dexmedetomidine group $(\mathrm{P}<0.05)$. As a result, dexmedetomidine performed as effectively and safely as midazolam when used as a sedative in upper gastroscopy; it was superior to midazolam with regard to retching, rate of side effects and endoscopist satisfaction. It was concluded that dexmedetomidine may be a good alternative to midazolam to sedate patients for upper endoscopy.

\section{Key Words: Dexmedetomidine; Endoscopy; Midazolam; Sedation}

Une comparaison entre la dexmédétomidine et le midazolam utilisés pour la sédation des patients pendant l'endoscopie supérieure : Une étude aléatoire prospective

La présente étude aléatoire prospective visait à explorer et à comparer l'inocuité et l'efficacité de la dexmédétomidine par rapport au midazolam comme sédatif en vue d'une gastroscopie Au total, 50 patients adultes ( 25 patients qui prenaient de la dexmédétomidine et 25 , du midazolam) de 18 à 60 ans, classés I ou II selon le système de classification de l'état physique de l'American Society of Anesthesiologists. Un bref questionnaire a été utilisé pour colliger les données démographiques. Les patients étaient invités à classer leur angoisse, leur satisfaction envers les soins jusque-là et les malaises qu'ils prévoyaient ressentir sur une échelle analogique visuelle. Les paramètres suivants ont été mesurés sur une base continue et enregistrés toutes les minutes : rythme cardiaque, tension artérielle moyenne, saturation en oxygène de l'hémoglobine et fréquence respiratoire. Les deux groupes étaient semblables pour ce qui est de l'âge, de l'indice de masse corporelle, du sexe, de l'éducation, de la durée de l'endoscopie et de l'utilisation d'éthanol ou de tabac. Après l'intervention, le temps de récupération complet, la tension artérielle moyenne, le rythme cardiaque, la fréquence respiratoire et la saturation en oxygène de l'hémoglobine étaient similaires dans les deux groupes. Les deux groupes possédaient également de faibles taux de perception de nausées, de malaises et d'angoisse pendant l'intervention $(\mathrm{P}>0,05)$ et de forts taux de satisfaction $(90,1 \pm 3,0$ pour la dexmédétomidine par rapport à $84,9 \pm 4,5$ pour le midazolam, $\mathrm{P}>0,05)$. Les haut-le cœur et la satisfaction endoscopique différaient considérablement chez les patients qui prenaient de la dexmédétomidine par rapport à ceux qui prenaient du midazolam $(88,8 \pm 6,5$ par rapport à $73,5 \pm 16,4, \mathrm{P}<0,05$; et 20,6 $\pm 4,4$ par rapport à 45,2 $\pm 6,0, \mathrm{P}<0,001)$. Au sein du groupe qui prenait du midazolam, le nombre de patients qui ont souffert d'effets indésirables était supérieur à celui du groupe qui prenait de la dexmédétomidine $(\mathrm{P}<0,05)$. Par conséquent, la dexmédétomidine fonctionnait de manière tout aussi sécuritaire et tout aussi efficace que le midazolam sous forme de sédatif en cas de gastroscopie supérieure, mais était mieux tolérée que le midazolam pour ce qui est des haut-le-cœur, du taux d'effets indésirables et de la satisfaction endoscopique. On a conclu que la dexmédétomidine est une bonne solution de rechange au midazolam pour assurer la sédation des patients en cas d'endoscopie supérieure.
$\mathrm{D}$ iagnostic esophagogastroduodenal endoscopy (EGD) is one of the most common invasive outpatient procedures performed in the western world, and accounts for $90 \%$ of all upper gastrointestinal endoscopic procedures (1). The most widely used form of sedation is the combination of a benzodiazepine, which has amnesic, anxiolytic and sedative properties, with an opioid, providing analgesia, synergistic sedation with benzodiazepines and additional amnesia (2). Intravenous benzodiazepines are known to reduce patient discomfort and increase tolerance to upper gastrointestinal endoscopy. Sedated patients appear to be more willing to undergo a repeat procedure if necessary. However, these sedatives frequently cause significant oxygen desaturation and, occasionally, a cardiopulmonary complication, but rarely death $(2,3)$.

\footnotetext{
${ }^{1}$ Department of Anesthesiology; ${ }^{2}$ Department of Gastroenterology; Abant Izzet Baysal University, School of Medicine, Konuralp/Duzce;

${ }^{3}$ Department of Internal Medicine, Abant Izzet Baysal University, School of Medicine, Golkoy/Bolu, Turkey

Correspondence: Dr Yavuz Demiraran, Osmaniye Mah Prestij Konutlari, Kat: 3, Daire: 24, Akcakoca, Duzce, Turkey 81100.

Telephone 90-0380-611-6761, fax 90-0380-541-4213 or 90-0380-541-4105, e-mail demiryvz@yahoo.com

Received for publication July 11, 2006. Accepted August 28, 2006
} 
Dexmedetomidine is a highly selective alpha $a_{2}$-adrenoreceptor agonist with sedative, analgesic and antisialagogue effects. Dexmedetomidine offers hemodynamic stability, has minimal effects on respiration and has only minor effects on cognitive functions. The mean distribution half-life and the mean terminal half-life of dexmedetomidine are $8.6 \mathrm{~min}$ and $3.14 \mathrm{~h}$, respectively. Dexmedetomidine is metabolized in the liver, and excreted in urine $(95 \%)$ and feces $(4 \%)(4,5)$. Compared with clonidine, it is more selective for alpha ${ }_{2}$-adrenoreceptors, and acts as a full agonist in most pharmacological test models. Potentially desirable effects include decreased requirements for other anesthetics and analgesics, a diminished sympathetic response to stress and the potential for cardioprotective effects against myocardial ischemia, and minimal effects on respiration (6,7). Additionally, dexmedetomidine decreases salivary secretion, through sympatholitic and vagomimetic effects (6). Small-dose infusion of this drug in healthy volunteers provides sedation that can be easily reversed with verbal stimuli (8). It has been used to provide safe sedation and analgesia to improve patient tolerance during mechanical ventilation and fiberoptic intubation (9).

To our knowledge, there is no study in the literature detailing the effects of dexmetedomidine in upper endoscopy. We hypothesized that dexmedetomidine may be used for sedation in upper endoscopy, and may be as effective and safe as other standard techniques. For this purpose, we compared its effects on respiration, hemodynamics, retching, gagging, endoscopist and patient satisfaction, analgesia and sedation, and side effects with those of midazolam during upper endoscopy.

\section{METHODS}

The present study was approved by the local ethics committee, and written informed consent was obtained from all of the participants. It was a prospective, randomized trial, and all elective patients who met the selection criteria and were undergoing EGD between January 2005 and January 2006 were included. A total of 50 adult patients (aged 18 to 60 years, and who rated I and II on the American Society of Anesthesiologists physical status classification system) were enrolled in the study. A brief questionnaire was administered that collected demographic data and asked patients to estimate their anxiety, satisfaction with care to date, expected amounts of gagging and discomfort during procedure, by using the visual analogue scale (VAS). The highest completed level of education was also obtained ( 1 = grammar school, 2 = high school, $3=$ college and 4 = graduate school).

During the procedure, the following parameters were measured continuously, and recorded every minute: heart rate, mean arterial pressure, hemoglobin oxygen saturation $\left(\mathrm{SpO}_{2}\right)$ and respiratory rate (Nihon Kohden Life Scope 9 monitor, Nihon Kohden Corporation, Japan). Administration of any medication, apart from the study protocol, and occurrences of complications and side effects (strong vertigo, nausea, vomiting, gagging and retching) were recorded. In case of serious adverse events, the patients were observed in hospital for at least $12 \mathrm{~h}$.

A computer-generated randomization list was used to assign patients to one of two groups. All patients received four squirts of topical lidocaine spray (Xylocaine, AstraZeneca Inc, Turkey) for pharyngeal anesthesia before EGD. In the dexmedetomidine group, conscious sedation was induced with an intravenous infusion of $1 \mu \mathrm{g} / \mathrm{kg}$ dexmedetomidine (Precedex, Abbot Laboratories, USA) via a syringe infusion AP22 pump (ASCOR SA, Poland) over a $10 \mathrm{~min}$ period before EGD, followed by an infusion of $0.2 \mu \mathrm{g} / \mathrm{kg} / \mathrm{h}$ dexmedetomidine $(n=25)$. In the midazolam group $(n=25)$,
$0.07 \mathrm{mg} / \mathrm{kg}$ dose (total dose $5 \mathrm{mg}$ ) of midazolam (Dormicum, F Hoffmann-La Roche Ltd, Switzerland) was adminstered via intravenous injection before EDG.

The depth of sedation was followed up by an observer who was not involved in the procedure by using a four-point somnolence score $(4$ = fully alert, 3 = awake but lethargic, $2=$ spontaneous eye closure but responsive to voice and $1=$ responds only to shaking or prodding) (10). When the patient achieved a sedation level of 2, endoscopic intubation was commenced. The time to reach this sedation level was also recorded. All gastroscopies were performed by the same experienced endoscopist with a multipurpose video gastroscope (Olympus GIF-XQ30, Olympus Corporation, Japan), $9.8 \mathrm{~mm}$ in diameter, $2.8 \mathrm{~mm}$ channel and $103 \mathrm{~cm}$ in working length. Sedation and monitoring were performed by the same anesthesiologist in all patients. The subjects, the research nurse - who conducted all preand postprocedural patient assessments - and the recovery room personnel were blinded to the type of medication used in the sedation. The randomization was conducted in the procedure room; thus, the endoscopist and the procedure room personnel were not blinded to the patient's sedation regimen.

\section{Patients' assessments}

The same research nurse, who was blinded to the type of sedation, conducted all evaluations before and after the procedures. Patients' assessment of tolerance to EGD was carried out at least $1 \mathrm{~h}$ after the procedure. Patient assessments of pain, gagging, anxiety and satisfaction were obtained before the procedure and in the recovery room at the time of discharge using the VAS (10-13). Patients were asked to place a vertical mark on a $100 \mathrm{~mm}$ straight line labelled only with descriptors at each end to represent procedural pain, gagging and anxiety $(0=$ none, $100=$ severe; for all $)$. Satisfaction before the procedure in the gastroenterology department $(0=$ very dissatisfied, $100=$ extremely satisfied) was also assessed.

\section{Endoscopist's assessment}

All endoscopies were carried out by the same endoscopist. Immediately after endoscopy, endoscopists were given a VAS to rate patient discomfort $(0=$ none, $100=$ severe $)$, gagging $(0=$ none, $100=$ severe $)$, retching $(0=$ none, $100=$ severe $)$, overall satisfaction with the patient's sedation level $(0=$ very dissatisfied, $100=$ very satisfied $)$ and technical difficulty $(0=$ easy, $100=$ very demanding $)$.

\section{Discharge scoring}

A recovery score after the procedure, adopted from Kankaria et al (12), was implemented 15 min after removal of the endoscope and every 15 min thereafter, until a discharge score of 10 of 10 was reached. For the scoring system, patients were assigned points of 0,1 or 2 for each of the following categories: activity (inability to move limbs, or ability to move two or four limbs with or without command); respiration (evidence of apnea, laboured breathing or normal breathing pattern); circulation (blood pressure compared with baseline before sedation); consciousness (fully awake or arousable); and skin color (pink or cyanotic). A maximum score for a healthy adult is 10 . The same research nurse who was blinded to the type of sedation used also conducted all the discharge assessments.

\section{Exclusion criteria}

Patients younger than 18 years of age, hypertension, prior gastrectomy, psychiatric diseases or long-term psychiatric drug addiction, chronic use or addiction to opiates or sedatives, presence of neoplastic or other serious concomitant diseases, previous adverse reactions to any medication used in the present study, a baseline 
TABLE 1

Demographic data

\begin{tabular}{lccc}
\hline Variable & $\begin{array}{c}\text { Midazolam } \\
\text { group } \\
(\mathbf{n = 2 5 )}\end{array}$ & $\begin{array}{c}\text { Dexmedetomidine } \\
\text { group } \\
\text { (n=25) }\end{array}$ & $\mathbf{P}$ \\
\hline Age, years & $43.3 \pm 13.2$ & $42.2 \pm 14.4$ & 0.58 \\
Sex, male/female & $9 / 16$ & $13 / 12$ & 0.26 \\
Body mass index, $\mathrm{kg} / \mathrm{m}^{2 *}$ & $24.5 \pm 1.9$ & $24.3 \pm 2.1$ & 0.48 \\
Duration of endoscopy, min* & $9.03 \pm 1.2$ & $8.9 \pm 1.3$ & 0.66 \\
Ethanol, $\mathrm{n}$ & 3 & 2 & 0.46 \\
Smoking, $\mathrm{n}$ & 10 & 8 & 0.84 \\
Education level, $\mathrm{n}$ & & & \\
1 & 14 & 11 & 0.76 \\
2 & 5 & 6 & 0.71 \\
3 & 3 & 4 & 0.65 \\
4 & 3 & 4 & 0.65 \\
\hline
\end{tabular}

Education level: 1 = grammar school, 2 = high school, $3=$ college and 4 = graduate school. *Mean $\pm S D$

TABLE 2

Indications for esophagogastroduodenal endoscopy

\begin{tabular}{lccc}
\hline Variable, $\mathbf{n}$ & $\begin{array}{c}\text { Midazolam } \\
\text { group } \\
(\mathbf{n = 2 5 )}\end{array}$ & $\begin{array}{c}\text { Dexmedetomidine } \\
\text { group } \\
(\mathbf{n = 2 5 )}\end{array}$ & $\mathbf{P}$ \\
\hline Dysphagia & 2 & 1 & 0.55 \\
Esophageal reflux symptoms & 7 & 6 & 0.74 \\
Dyspepsia & 16 & 18 & 0.54 \\
\hline
\end{tabular}

systolic blood pressure less than $90 \mathrm{mmHg}$, an American Society of Anesthesiologists physical status classification of III, IV or V, pain in the gastrointestinal tract and those who were pregnant, were excluded from the study.

Statistical analysis

Data were expressed as mean values $\pm \mathrm{SD}$ or as the number of patients and percentages. Fisher's exact, Student's $t$ and $\chi^{2}$ tests were used in the comparisons of the quantitative and qualitative values of the two groups. $\mathrm{P}<0.05$ was considered statistically significant. Statistical analyses were performed using SPSS version 10.0 (SPSS Inc, USA) for Windows (Microsoft Co, USA).

\section{RESULTS}

All 50 patients (25 in each group) completed the study. Demographic data for the two groups are summarized in Table 1. There were no statistically significant differences between the groups with regard to age, body mass index, sex, degree of education, duration of endoscopy, and ethanol or tobacco use. All patients were examined easily by endoscopes. Indications for EGD of the patients were similar in both groups (P>0.05) (Table 2).

The preprocedural scores using the VAS showed that the sedation of the two groups was similar with respect to expected discomfort and gagging, level of anxiety and satisfaction of care (Table 3). After the procedure, low levels of procedural gagging and discomfort were detected in both groups. High satisfaction levels were seen in both groups $(90.1 \pm 3.0$ for dexmedetomidine versus $84.9 \pm 4.5$ for midazolam; $\mathrm{P}=0.72$ ). The anxiety score after the procedure was lower in patients receiving dexmedetomidine
TABLE 3

Preprocedural visual analogue scale scores*

\begin{tabular}{lccc}
\hline Variable & $\begin{array}{c}\text { Midazolam } \\
\text { group } \\
(\mathbf{n = 2 5 )}\end{array}$ & $\begin{array}{c}\text { Dexmedetomidine } \\
\text { group } \\
\mathbf{( n = 2 5 )}\end{array}$ & $\mathbf{P}$ \\
\hline Expected discomfort & $24.8 \pm 4.1$ & $26.3 \pm 4.9$ & 0.34 \\
Expected gagging & $23.5 \pm 3.4$ & $23.4 \pm 3.6$ & 0.86 \\
Anxiety score & $33.03 \pm 4.9$ & $32.9 \pm 5.01$ & 0.86 \\
Expected satisfaction & $86.7 \pm 3.8$ & $87.8 \pm 3.0$ & 0.99 \\
\hline
\end{tabular}

${ }^{*}$ Mean $\pm S D$

TABLE 4

Postprocedural visual analogue scale scores*

\begin{tabular}{lccc}
\hline Variable & $\begin{array}{c}\text { Midazolam } \\
\text { group } \\
(\mathbf{n = 2 5})\end{array}$ & $\begin{array}{c}\text { Dexmedetomidine } \\
\text { group } \\
\mathbf{( n = 2 5 )}\end{array}$ & $\mathbf{P}$ \\
\hline Discomfort & $5.9 \pm 1.2$ & $6 \pm 1.2$ & 0.56 \\
Gagging & $8.3 \pm 3.7$ & $8.1 \pm 3.1$ & 0.59 \\
Anxiety & $27.1 \pm 4.2$ & $19.9 \pm 2.9$ & 0.21 \\
Satisfaction & $84.9 \pm 4.5$ & $90.1 \pm 3.0$ & 0.72 \\
\hline
\end{tabular}

${ }^{*}$ Mean $\pm S D$

TABLE 5

Endoscopist visual analogue scale scores*

\begin{tabular}{lccc}
\hline Variable & $\begin{array}{c}\text { Midazolam } \\
\text { group } \\
(\mathbf{n = 2 5})\end{array}$ & $\begin{array}{c}\text { Dexmedetomidine } \\
\text { group } \\
\mathbf{( n = 2 5 )}\end{array}$ & $\mathbf{P}$ \\
\hline Discomfort & $26.3 \pm 4.3$ & $20.0 \pm 3.7$ & 0.28 \\
Gagging & $27.1 \pm 4.2$ & $19.9 \pm 2.9$ & 0.21 \\
Retching & $45.2 \pm 6.0$ & $20.6 \pm 4.4$ & $<0.001$ \\
Satisfaction & $73.5 \pm 16.4$ & $88.8 \pm 6.5$ & 0.029 \\
Technical difficulty & $55.0 \pm 4.6$ & $55.8 \pm 4.1$ & 0.89 \\
\hline
\end{tabular}

${ }^{*}$ Mean $\pm S D$

than those receiving midazolam $(19.9 \pm 2.9$ versus $27.1 \pm 4.2$, $\mathrm{P}=0.21)$, but this difference did not reach statistical significance (Table 4).

The endoscopist rating of the degree of technical difficulty, gagging and discomfort associated with the procedure was not significant between the sedation groups, but endoscopist satisfaction on sedation of patients was significantly higher in the patients receiving dexmedetomidine than those receiving midazolam (88.8 \pm 6.5 versus $73.5 \pm 16.4 ; \mathrm{P}=0.029$ ) (Table 5). Retching was significantly lower in patients receiving dexmedetomidine compared with those receiving midazolam (20.6 \pm 4.4 versus 45.2 $\pm 6.0 ; \mathrm{P}<0.001)$.

The average to full recovery time, and independent transfer numbers were found to be similar between the groups. There were no differences between the two groups in the number of patients who recovered in the 15th, 30th and 45th minute (Table 6). The occurrence of side effects was not different between groups. However, total number of patients who had one or more side effects was higher in the midazolam group $(\mathrm{P}<0.05)$ (Table 7). Hemodynamic parameters were similar in both groups $(\mathrm{P}>0.05)$ (Figure 1).

\section{DISCUSSION}

Although conscious sedation is the method most widely used to reduce anxiety in patients undergoing EGD, its actual role is still 
TABLE 6

Recovery data

\begin{tabular}{lccc}
\hline Variable & $\begin{array}{c}\text { Midazolam } \\
\text { group } \\
(\mathbf{n = 2 5})\end{array}$ & $\begin{array}{c}\text { Dexmedetomidine } \\
\text { group } \\
(\mathbf{n = 2 5 )}\end{array}$ & $\mathbf{P}$ \\
\hline Independent transfer, $\mathrm{n}$ & 17 & 13 & 0.11 \\
Time to full recovery, min & $37.6 \pm 11$ & $42 \pm 12.5$ & 0.30 \\
Patients fully recovered, $\mathrm{n}(\%)$ & & & \\
$15 \mathrm{~min}$ & $12(48)$ & $10(40)$ & 0.56 \\
$30 \mathrm{~min}$ & $20(80)$ & $18(72)$ & 0.74 \\
$45 \mathrm{~min}$ & $25(100)$ & $25(100)$ & 0.99 \\
\hline
\end{tabular}

${ }^{*}$ Mean \pm SD
TABLE 7

Adverse events

\begin{tabular}{lcc}
\hline Variable & $\begin{array}{c}\text { Midazolam } \\
\text { group } \\
(\mathbf{n = 2 5 )}\end{array}$ & $\begin{array}{c}\text { Dexmedetomidine } \\
\text { group } \\
(\mathbf{n = 2 5})\end{array}$ \\
\hline Bradycardia, $\mathrm{n}$ & 2 & 4 \\
Apnea, $\mathrm{n}$ & 1 & 0 \\
Cough, $\mathrm{n}$ & 9 & 0 \\
Desaturation, $\mathrm{n}$ & 2 & 0 \\
Vomiting, $\mathrm{n}$ & 2 & 0 \\
Nausea, $\mathrm{n}$ & 2 & 1 \\
Total, $\mathrm{n}(\%)$ & $18(52)$ & $5(20)$
\end{tabular}

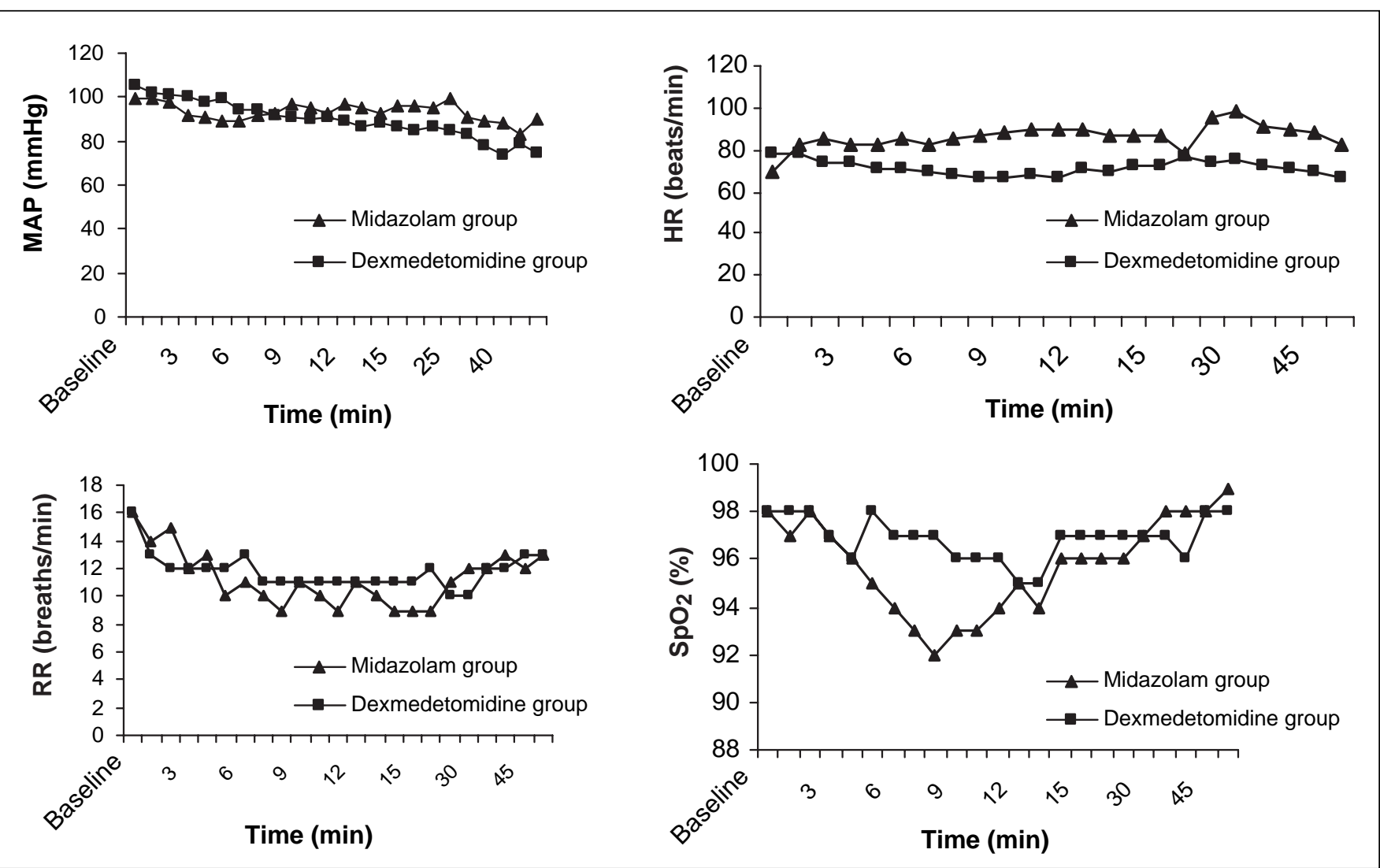

Figure 1) Mean values of mean arterial pressure (MAP), heart rate $(\mathrm{HR})$, respiratory rate $(\mathrm{RR})$ and hemoglobin oxygen saturation $\left(\mathrm{SpO}_{2}\right)$ determined over the course of the procedure (total $50 \mathrm{~min}$ )

an unresolved problem. With regard to sedation practice, very large differences exist among different countries, and sometimes among different units within the same country (14). Dexmedetomidine is a new drug that has been used in sedoanalgesia for short procedures and its use has been steadily increasing worldwide. However, the use of dexmedetomidine in adults undergoing EGD has not been fully evaluated; although some reports have been established about its use in colonoscopy. Jalowiecki et al (15) observed that dexmedetomidine provided a relatively satisfactory level of analgesia and conscious sedation without clinically distinguished respiratory side effects in patients undergoing colonoscopy. However, fentanyl supplementation (analgesic requirement) was required in $47 \%$ of patients in the dexmedetomidine group to achieve a satisfactory level of analgesia, and in patients given fentanyl, vertigo (five patients), nausea and vomiting (five patients), ventricular bigeminy (one patient), and hemodynamic instability with prolonged recovery were observed. In the present study, fentanyl was not used as an analgesic; satisfaction after the procedure was considerably good in both groups (Table 4). In addition, the dexmedetomidine group recovery time was not prolonged, and the number of other adverse events were lower than the midazolam group.

Mizuno et al (16) observed that sedation with intravenous midazolam during upper gastrointestinal endoscopy was useful to control the cardiovascular responses, and to induce amnesia. However, they suggested that decreases in the $\mathrm{SpO}_{2}$ should be monitored carefully. In the midazolam group, we observed apnea in one patient and decreased $\mathrm{SpO}_{2}$ in two patients; no deterioration 
in respiratory and cardiovascular parameters was observed in the dexmedetomidine group.

A combination of propofol, meperidine/fentanyl and midazolam was used in 100 adult patients by Cohen et al (17). Their study showed that endoscopy could be performed at a moderate level of sedation by combining a low dose of propofol with a narcotic agent and/or benzodiazepine, and that the use of a small dose of a narcotic agent and midazolam in combination with propofol does not prolong patient recovery. However, Vargo et al (18) reported that propofol led to significantly improved recovery to baseline activity compared with a combination of midazolam/meperidine. Additionally, they discovered 54 episodes of apnea/disordered respiration in 28 patients receiving a combination of midazolam/meperidine (mean duration $70.8 \mathrm{~s}$ ). Arian and Ebert (19) reported a sedation induction time of $25 \mathrm{~min}$ and a recovery time of $34 \mathrm{~min}$ with dexmedetomidine in adults. Although we did not use opioids or propofol, our results (10 min onset of sedation and 42 min recovery time) indicate that both induction and recovery time in dexmedetomidine sedation are suitable for upper endoscopy.

Abuksis et al (20) demonstrated that previous endoscopy experience could reduce anxiety level and influence patients' compliance. Trevisani et al (21) suggested that low-dose conscious sedation with midazolam could improve the tolerance to EGD, in accordance with a previous trial reporting a lower discomfort in sedated patients than in controls (2). In our study, patient's discomfort, gagging, anxiety and satisfaction scores were satisfactory in both groups after the procedure.

\section{REFERENCES}

1. Quine MA, Bell GD, McCloy RF, et al. Prospective audit of upper gastrointestinal endoscopy in two regions of England: Safety, staffing, and sedation methods. Gut 1995;36:462-7.

2. Froehlich F, Schwizer W, Thorens J, Kohler M, Gonvers JJ, Fried M. Conscious sedation for gastroscopy: Patient tolerance and cardiorespiratory parameters. Gastroenterology 1995;108:697-704.

3. Arrowsmith JB, Gerstman BB, Fleischer DE, Benjamin SB. Results of the American Society for Gastrointestinal Endoscopy/US Food and Drug Administration collaborative study on complication rates and drug use during gastrointestinal endoscopy. Gastrointest Endosc 1991;37:421-7.

4. Venn RM, Karol MD, Grounds RM. Pharmacokinetics of dexmedetomidine infusions for sedation of postoperative patients requiring intensive care. Br J Anaesth. 2002;88:669-75.

5. Aanta R, Schienin M. Alpha 2-adrenergic agents in anaesthesia. Acta Anaesthesiol Scand 1993;37:433-48.

6. Kamibayashi T, Maze M. Clinical uses of alpha2-adrenergic agonists. Anesthesiology 2000;93:1345-9.

7. Wijeysundera DN, Naik JS, Beattie WS. Alpha-2 adrenergic agonists to prevent perioperative cardiovascular complications: A meta-analysis. Am J Med 2003;114:742-52.

8. Belleville JP, Ward DS, Bloor BC, Maze M. Effects of intravenous dexmedetomidine in humans. I. Sedation, ventilation, and metabolic rate. Anesthesiology 1992; 77:1125-33.

9. Avitsian R, Lin J, Lotto M, Ebrahim Z. Dexmedetomidine and awake fiberoptic intubation for possible cervical spine myelopathy: A clinical series. J Neurosurg Anesthesiol 2005;17:97-9.

10. Demiraran Y, Kocaman B, Akman RY. A comparison of the postoperative analgesic efficacy of single-dose epidural tramadol versus morphine in children. Br J Anaesth 2005;95:510-3.

11. Revill SI, Robinson JO, Rosen M, Hogg MI. The reliability of a linear analogue for evaluating pain. Anaesthesia 1976;31:1191-8.

12. Kankaria A, Lewis JH, Ginsberg G, et al. Flumazenil reversal of psychomotor impairment due to midazolam or diazepam for conscious sedation for upper endoscopy. Gastrointest Endosc $1996 ; 44: 416-21$.
Upper endoscopy is an unpleasant examination because of the retching and nausea experienced during the procedure. During endoscopy, because of air insufflation and gastric irritation caused by the endoscope, the gastric walls are distended and this stimulates the vomiting centre via sympathetic and vagal afferents (22). The abnormal motility patterns observed during retching and vomiting preclude an optimum field of vision during endoscopy. Although conscious sedation with diazepam or midazolam, which are given alone or with an opioid such as intravenous meperidine, is used to overcome these effects, these medications are sometimes not helpful and most sedated patients are still able to retch (23). In our study, retching was found to be significantly lower and endoscopist satisfaction was higher in the dexmedetomidine group. Decreasing of retching reflex in the dexmedetomidine group may be due to its sympatholitic and vagomimetic effects. These findings demonstrate that dexmedetomidine may be safely and effectively used in patients undergoing upper endoscopy and can be offered to patients on a routine basis.

\section{CONCLUSION}

Dexmedetomidine was found to be similar to midazolam with regard to gagging, patient satisfaction, patient discomfort, anxiety scores and recovery time; it was superior with regard to endoscopist satisfaction, retching and the total number of patients having any type of side effects. Dexmedetomidine, being safe and effective, seems to be a good alternative to midazolam for sedation of patients during upper endoscopy.

13. Froehlich F, Thorens J, Schwizer W, et al. Sedation and analgesia for colonoscopy: Patient tolerance, pain, and cardiorespiratory parameters. Gastrointest Endosc 1997;45:1-9.

14. Bell GD. Premedication, preparation, and surveillance. Endoscopy 2002;34:2-12.

15. Jalowiecki P, Rudner R, Gonciarz M, Kawecki P, Petelenz M, Dziurdzik P. Sole use of dexmedetomidine has limited utility for conscious sedation during outpatient colonoscopy. Anesthesiology 2005;103:269-73

16. Mizuno J, Matsuki M, Gouda Y, Nishiyama T, Hanaoka K. [Sedation with intravenous midazolam during upper gastrointestinal endoscopy - changes in hemodynamics, oxygen saturation and memory.] Masui 2003;52:976-80.

17. Cohen LB, Hightower CD, Wood DA, Miller KM, Aisenberg J. Moderate level sedation during endoscopy: A prospective study using low-dose propofol, meperidine/fentanyl, and midazolam. Gastrointest Endosc 2004;59:795-803.

18. Vargo JJ, Zuccaro G Jr, Dumot JA, et al. Gastroenterologistadministered propofol versus meperidine and midazolam for advanced upper endoscopy: A prospective, randomized trial. Gastroenterology 2002;123:8-16.

19. Arian SR, Ebert TJ. The efficacy, side effects, and recovery characteristics of dexmedetomidine versus propofol when used for intraoperative sedation. Anesth Analg 2002;95:461-6.

20. Abuksis G, Mor M, Segal N, et al. A patient education program is cost-effective for preventing failure of endoscopic procedures in a gastroenterology department. Am J Gastroenterol 2001;96:1786-90.

21. Trevisani L, Sartori S, Gaudenzi P, et al. Upper gastrointestinal endoscopy: Are preparatory interventions or conscious sedation effective? A randomized trial. World J Gastroenterol 2004;10:3313-7.

22. Keeffe EB. Towards safer endoscopy. In: Cotton PB, Tytgat GNJ, Williams CB, Bowling TE, eds. Annual of Gastrointestinal Endoscopy. London: Rapid Science Publisher, 1997:1-14.

23. Tarcin O, Gurbuz AK, Pocan S, Keskin O, Demirturk L. Acustimulation of the Neiguan point during gastroscopy: Its effects on nausea and retching. Turk J Gastroentrerol 2004;15:258-62. 


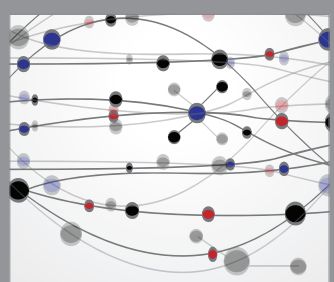

The Scientific World Journal
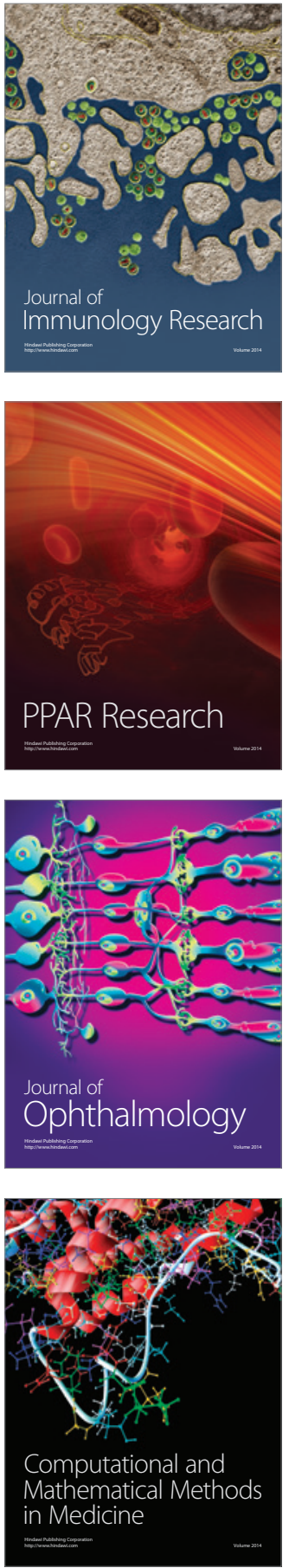

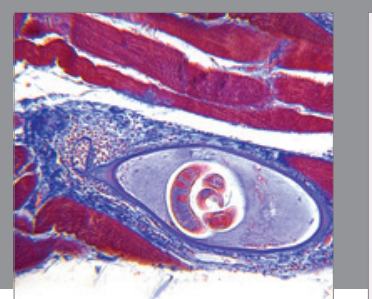

Gastroenterology Research and Practice

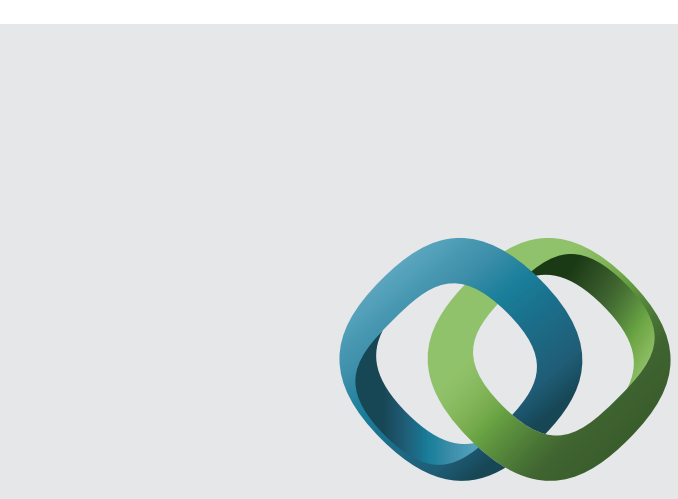

\section{Hindawi}

Submit your manuscripts at

http://www.hindawi.com
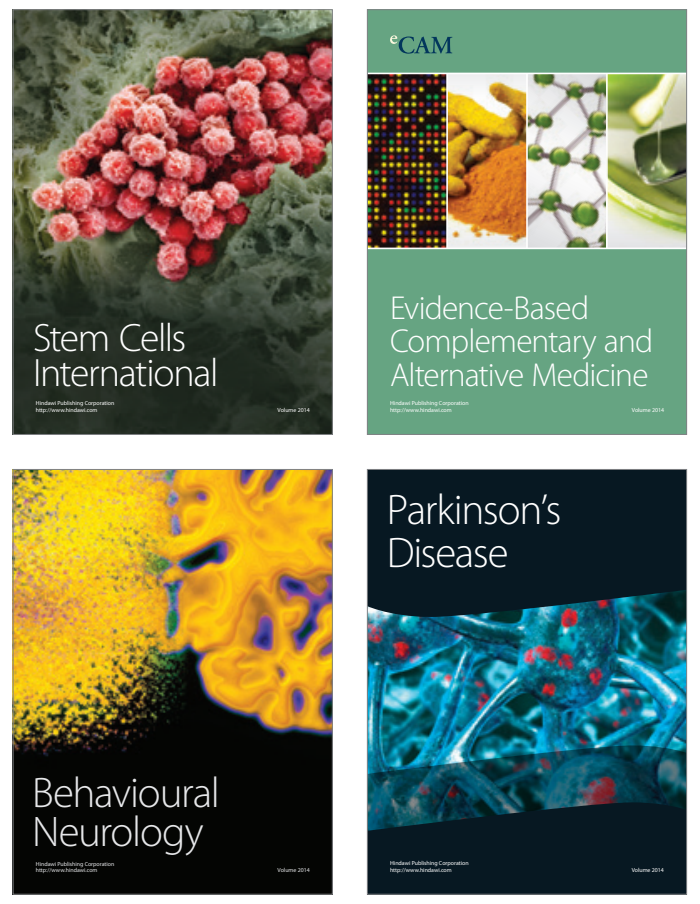
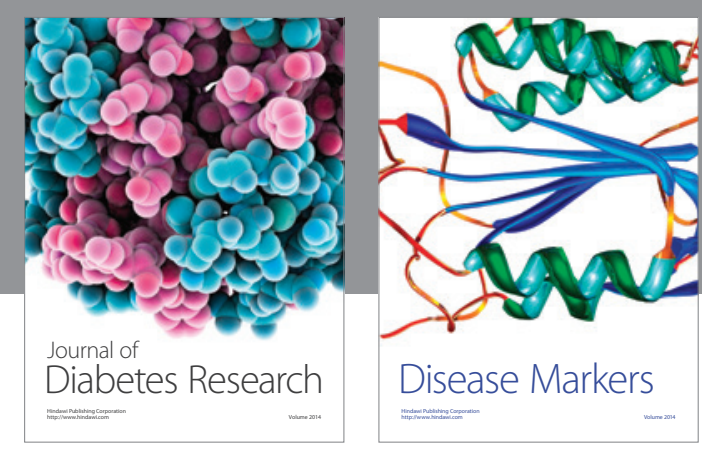

Disease Markers
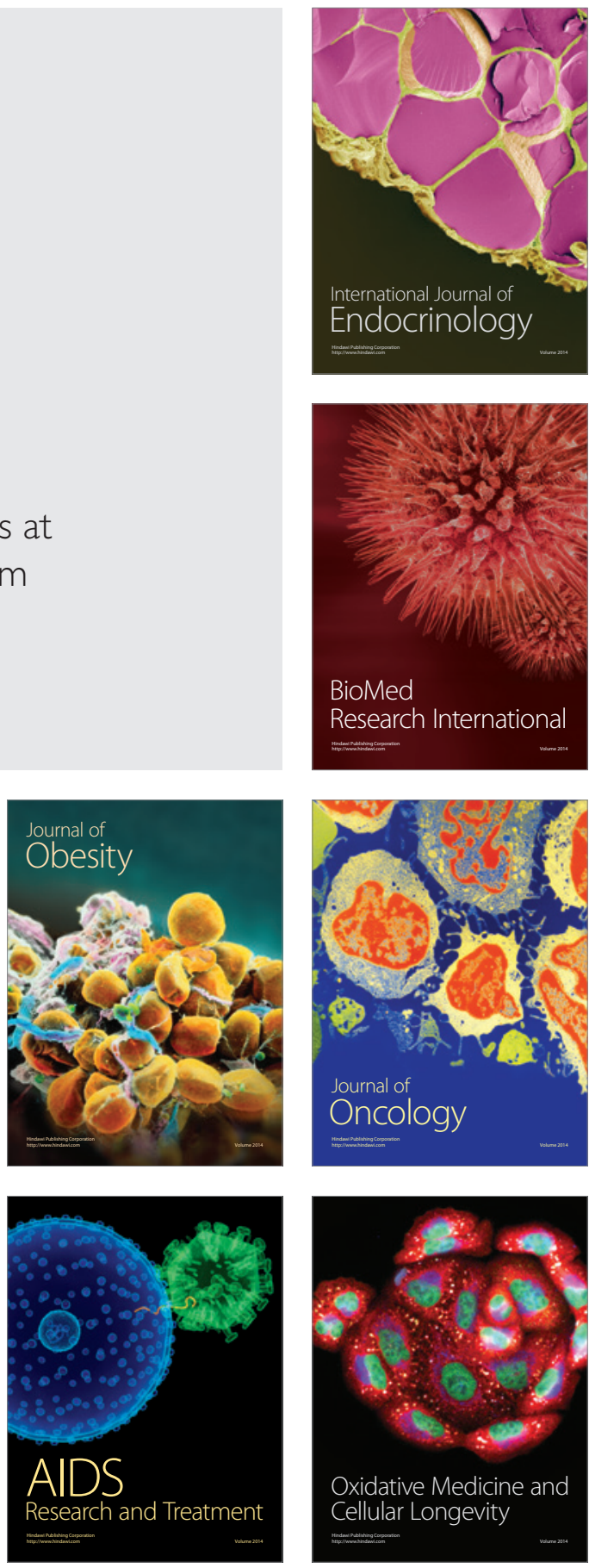